\title{
Music Use in Exercise: A Questionnaire Study
}

\author{
Rachel Hallett and Alexandra Lamont
}

\begin{abstract}
Although there is much research looking at music's effects on sport and exercise performance, little is known about exercisers' own application of music during workouts. An online questionnaire exploring its relationship with gender, formal music training, personality and $5 k$ performance was completed by 282 regularly exercising participants (159 women, 116 men, 6 undisclosed, $\mathrm{M}_{\text {age }}=37.68, \mathrm{SD}=$ 10.16). Women were more likely to use music during exercise than men $(\mathrm{p}=.011)$, and to synchronise to the beat $(\mathrm{p}=.002)$, and women's preferences were spread over a range of pop, rock and dance music, whereas men's were focused on rockrelated styles. Being open to new experiences was associated with preferring rock, metal and indie music $(\mathrm{p}=.042)$ and those who intentionally synchronised their movements were more open to new experiences than non-synchronisers $(\mathrm{p}=.003)$, although a minority of participants synchronised intentionally. Most gym users listened to their own music in the gym rather than music played by the facility. These findings provide new insights into exercise music use, challenging assumptions that formal music training affects how music is applied in exercise, and that synchronisation to the beat is the 'norm' for exercisers listening to music.
\end{abstract}

\section{Keywords}

Music and media, Quantitative, Sports and media, Music and exercise 
It is well established that exercise has physical benefits, reducing the risk of premature mortality (Warburton, Charlesworth, Ivey, Nettlefold \& Bredin, 2010) and chronic conditions such as cardiovascular disease (Myers, 2008). Exercise can also help improve general wellbeing, address symptoms of depression and act as a preventative measure in mental health (Stanton, Happell \& Reaburn, 2014). However, it is well-recognised that many people exercise too little, and struggle with motivation.

Music is used widely during workouts, and can increase motivation and positive affect among exercisers (Hutchinson et al., 2011; Laukka \& Quick, 2013). It may be self-selected or other selected, such as tracks played over a gym's PA system or chosen by the instructor for an exercise-to-music class. Technological developments have extended the options for selfselected music during exercise, with MP3 players and mobile phones holding large music libraries. However, little is known about exercisers' own choices of music for their workouts, nor how they are used.

There is much research regarding music use in everyday life. Its main application is to manage mood and affect (Juslin \& Sloboda, 2010; Skånland, 2013), and DeNora (2000) notes that listeners are adept at selecting tracks which will deliver the required emotional effect. Chamorro-Premuzic and Furnham (2007) suggest that music may also be useful to overcome the monotony of activities such as housework and jogging, particularly for those with high levels of extraversion who thrive in highly stimulating environments.

Research has explored music use as a motivational device in sports and exercise, primarily to enhance performance. Studies have considered its effects on intensity (Edworthy \& Waring, 2006; Waterhouse, Hudson \& Edwards, 2010) and rate of perceived exertion (RPE) (Dyrland \& Wininger, 2008; Terry, Karageorghis, Saha \& D'Auria, 2012), as well as affect (Bird et al., 2016; Edworthy \& Waring, 2006; Terry et al., 2012) and strength (Biagini et al., 2012; Razon, Basevitch, Land, Thompson \& Tenenbaum, 2009), with favourable results. Edworthy and Waring (2006) found tempo affected speed of walking or running on a treadmill, and moderated the effects of volume, while Waterhouse et al. (2010) found participants increased their intensity on a stationary bike when tempo was increased by a small amount (the participants did not recognise the tempo difference, instead reporting that some versions sounded 'brighter'), and that faster music was enjoyed more. Razon et al. (2009) found rate of perceived exertion (RPE) in strength exercise was moderated by music through a dissociative strategy, and Hutchinson and Karageorghis (2013) found individual differences in dominant attentional style affected RPE: dissociative styles were associated with lower RPE at higher 
intensity activity than associative styles. Music's capacity to reduce RPE has not been shown consistently, although this may be due to much of the research focusing on high intensity exercise, where music use may not so easily distract from the sensations of effort (Karageorghis \& Priest, 2012a).

Karageorghis and Priest, in their review of the field (2012a), note that listening to music during repetitive-movement endurance exercise reduces perceived exertion, increases output and improves affect. They define motivating music as "that which controls arousal, reduces perceptions of exertion and improves mood" (p.46). In the second part of their review (2012b), they suggest that motivation and affect are linked, proposing that motivational music's capacity to increase positive affect leads to an effect on psychological states, even at high intensities, and that this may increase adherence to exercise, although this is speculative.

Clark, Baker and Taylor (2016) extend their systematic review of music use in physical activity to present a meta-theory of possible factors. They outline interactions of cultural background, entrainment (synchronisation with music of physiological characteristics such as heartbeat or motor activities), subjective experience and physiological arousal with psychological, neurophysiological and behavioural responses. This suggests a range of physical and psychological outcomes are relevant to music use in exercise, and Clark et al. suggest it is this interplay which may lead to adherence.

Clark et al.'s findings (2016) overlap with the BRECVEMA model (Juslin, Harmat \& Eerola, 2013) of mechanisms underpinning emotional responses to music in more general listening, which incorporates eight levels: brain stem reflex, rhythmic entrainment, evaluative conditioning, contagion, visual imagery, episodic memory, musical expectancy and aesthetic judgement. These represent increasingly sophisticated processing of music, with brain stem reflex a response to basic elements of the music such as speed or volume, whereas aesthetic judgement relates to criteria developed by the listener relating to music content, social context and cultural familiarity (Juslin, 2013). The higher levels (visual imagery, episodic memory, musical expectancy and aesthetic judgement) could be compared to cultural background and subjective experience in Clark et al.'s model, while the lower levels (brain stem reflex, rhythmic entrainment, evaluative conditioning and contagion) suggest similarities to Clark et al.'s physiological and neurophysiological responses. Juslin et al.'s rhythmic entrainment in particular is comparable to Clark et al.'s rhythmic entrainment/synchronisation; whether entrainment is unconscious (heart rate corresponding to music's beats per minute) or conscious (stepping in time to music), this is particularly relevant to exercise contexts.. 
These similarities suggest that more general theories of response to music in everyday life may be relevant to exercise contexts. Juslin et al. (2013) present their model as an underpinning for emotional responses to music, although they also note physiological changes that occur alongside the emotional response: emotion is experienced by the listener, rather than simply recognised as something the artist is trying to express. Clark et al. (2016) extend their theory beyond emotion, presenting a hypothesis that the mechanisms they identify contribute towards exercise adherence through the interaction of physiology and psychology. This area of research is at an early stage but it underlines the likelihood that emotional response to music is interlinked with broader psychological, behavioural and physiological responses, and that this is why music may be useful as a tool to assist with exercise adherence.

An additional factor not addressed by Clark et al. (2016) or Juslin et al. (2013) is the possibility that music assists with dissociation and may moderate the experience of discomfort or pain during exercise. Listening to music can moderate the experience of pain (Mitchell \& MacDonald, 2006; Mitchell, MacDonald and Knussen, 2008) and the control facilitated by self-selecting music (rather than listening to something someone else has chosen) may contribute. Mitchell and MacDonald (2006) note that participant choice appeared to be a factor in the effect of music on pain perception, and observed that participants chose a wide range of different styles, suggesting a piece of music's effects are not universal, but depend on individual associations. Krause, North and Hewitt (2015) suggest that control over choice of music in everyday listening may be the reason for increased engagement with and arousal from that particular material, while Sloboda, O'Neill and Ivaldi (2001) found control over music choice was the main moderating factor in improved mood.

A further aspect of music and exercise about which little is known is synchronisation, where movement coincides with the beat of the music. Synchronisation in walking has been found to take place only when participants were instructed to move in time with auditory cues (Mendonça, Oliveira, Fontes \& Santos, 2014), while in Hallett and Lamont's study of gym members (2015), only one reported synchronising movement to the beat, and described it as arising accidentally rather than being intentional. An exercise instructor in Priest and Karageorghis's qualitative study of exercise music use (2008) described a tendency to synchronise to the beat when exercising, inferring this was a usual practice; it is not clear, however, whether this participant was referring to instructing or his own use of music. In many exercise-to-music classes, synchronisation is fundamental to choreography, and it is perhaps surprising that so little synchronisation appears to take place in other exercise contexts, 
particularly given that most people are able to synchronise to a beat on request (Phillips-Silver et al., 2011).

Karageorghis et al. (2010) found a gender effect on synchronisation in a study where participants were asked to synchronise movements with the beat of the music. Women benefitted from synchronous music while men responded well to a metronome beat. The authors suggested that women's tendency to synchronise to music arises through more engagement with music and movement activities from childhood onwards when compared with men; nevertheless, social dancing differs from the study in that instructions to move to a beat are rarely given.

A further possible variable is formal music training. Research suggests that as little as 15 months' formal music training in early childhood can lead to structural changes in the brain associated with improved motor and auditory skills relating to music (Hyde et al., 2009). Chen, Penhune and Zatorre (2008) found musical training related to capacity for auditory-motor synchronisation, while Palmer and Griscom (2013) identified a link between increased levels of formal music training and decreased preference for harmonious music, although the mechanisms underpinning this are unclear. Music training may therefore affect exercise music preference and propensity to synchronise. However, individual preference is often not taken into account in exercise music research.

The work of Juslin et al. (2013) and Clark et al. (2016) acknowledges some level of individual differences in response to music, for example aesthetic judgement and episodic memory in the former, and cultural background and subjective experience in the latter. The competency individuals display in choosing music to suit their needs (DeNora, 2000) suggests exercisers' criteria may be applied to deliver a response consistent with Juslin et al.'s and Clark et al.'s theories. However, studies have often been carried out with researcher-selected music, or, in some cases, based on peer evaluations of a range of tracks using the Brunel Music Rating Inventory (BMRI) (Karageorghis, Terry \& Lane, 1999) and the updated BMRI-2 (Karageorghis, Priest, Terry, Chatzisarantis \& Lane, 2006), inventories of intrinsic musical factors which are scored to produce average track ratings. There are few studies using participants' self-selected music, or looking at the effects of exercisers' personal favourites. Biagini et al. (2012) found self-selected music may be beneficial for strength exercises involving explosive power, while Bharani, Sahu and Mathew (2004) found self-selected music was associated with increased stamina, exercising at higher heartrates, and decreased RPE. 
Continuing the theme of individual differences, personality traits have also been associated with musical preference for particular styles and genres. Rentfrow and Gosling (2003) found associations between Extraversion and enjoying 'Upbeat and Conventional' music such as pop, country and religious tracks, and 'Energetic and Rhythmic' music such as dance, soul and rap styles. Openness had a particularly strong association with liking 'Reflective and Complex' music (classical, jazz and blues), as well as a preference for 'Intense and Rebellious' styles such as rock, metal and alternative music, while having a negative association with Upbeat and Conventional preferences. These findings have not been consistent across the literature: Dunn, de Ruyter and Bouwhuis (2001) found relationships between Neuroticism and liking for classical music, and their findings did not support the four categories identified by Rentfrow and Gosling, although their sample was drawn from a general adult population, while Rentfrow and Gosling's participants were undergraduates. Furthermore, the types of music that might be considered suitable for exercise tend to be upbeat (Hallett \& Lamont, 2015), and preference and personality associations may differ from other everyday listening contexts. Hallett and Lamont's study was limited to gym exercise, and was qualitative, with 16 participants; gender differences that may be relevant in exercise contexts were not analysed statistically. There is, therefore, scope to identify general trends across a larger sample using quantitative methods, expanding the number of exercise activities covered. Although Rentfrow and Gosling (2003) did not find gender differences in personality and music preference correlations, preference differences have been identified, suggesting that men prefer heavier styles (Colley, 2008), but this has not been studied in exercise contexts.

Rentfrow and Gosling's four-type model (2003) has subsequently been revised to incorporate five types of music (Rentfrow et al., 2012): Mellow, Unpretentious, Sophisticated, Intense, and Contemporary (forming the acronym MUSIC). Again, these categories arise from studies based in North America, where the popularity profiles of different styles may differ from in other cultures. Although there may have been participants from other geographical areas (this is not specified), a substantial proportion of the sample was taken from the student population at the University of Texas. In their discussion of their findings, Rentfrow et al. note that four factors - Unpretentious, Sophisticated, Intense and Contemporary - consistently appear across studies, while the Mellow factor was present in around half the findings. This may be indicative of a framework closer to the original (Rentfrow \& Gosling, 2003) in some contexts. As popular music styles are themselves dynamic, any classification system is also likely to evolve. 
Musical preference may also involve perceived 'fit' of music to a particular situation. ${ }^{1}$ In North and Hargreaves' study of music preference in aerobics and yoga (1996), participants preferred arousing music for aerobics and calming music for yoga, reflecting the intensity of the activities. Dillman Carpentier and Potter (2007) note that fast-paced music in both classical and rock genres elicits greater levels of arousal than slow-paced music, which corresponds with Hallett and Lamont's finding (2015) regarding exercisers' preference for 'upbeat' music. The concept of fit is incorporated into Hargreaves, MacDonald and Miell's reciprocal feedback model (2005; see also Hargreaves, 2012), where an interplay is suggested between musical characteristics, and social/cultural contexts, situations and activities. Hallett and Lamont (2015) found that exercisers chose different music for gym and home environments, suggesting particular styles may 'fit' exercise contexts.

Many questions remain regarding how music is used by exercisers with autonomy to select their activity and the music that accompanies it. Little is known about what music is selected for exercise, nor why. The possible influence of formal music training on exercise music choice and behaviour such as synchronising has not been investigated. While music use in exercise is acknowledged by those using it as having a motivating effect (Hallett \& Lamont, 2015; Priest \& Karageorghis, 2008), the reasons for some people's preference for not using music while exercising have not been explored. Gender and personality have not been explored as possible influences on exercise music choice and application. Finally, the relationship between music use and general physical performance levels (rather than performance while listening to music) has received little attention.

Research questions arising from the apparent gaps in current literature are:

1. What music are people choosing to listen to while they exercise?

2. What criteria are they using to select exercise music?

3. Why do exercisers sometimes choose not to use music?

4. What are individuals' perceptions regarding whether they synchronise movements to the beat?

5. How does personality relate to preferred exercise music?

\footnotetext{
${ }^{1}$ The concept of 'fit' has similarities with mood management through music. Zillman's theory of mood management suggests that individuals are motivated to choose entertainment (including, but not restricted to, music) to generate or maintain positive mood. Knobloch and Zillman (2002) found that those experiencing low mood chose energetic, joyful music in an apparent attempt to generate more positive feelings.
} 
6. How does formal music training relate to music use in exercise?

7. How does gender relate to music use in exercise?

8. Can performance differences be identified between those who regularly listen to music during exercise and those who do not?

Because knowledge is scant in this area, we devised an investigative study using a questionnaire exploring formal music training, preferred exercise music, personality, 5k performance and propensity to synchronise to the beat, better to understand music use in exercise and possible variables underlying music-using behaviour. The aim was to create a picture of exercisers' preferences and music use in an environment where portable music access has increased considerably in recent years, identifying areas that are particularly relevant to future research.

In the following sections, we consider what kind of music is preferred for exercise, and how it is applied with regard to synchronised movement. This is in the context of various individual differences regarding personality, formal music training and performance when running or walking 5 kilometres, and the relationships between the variables are explored to identify possible reasons underpinning the way in which music is applied in exercise. We also examine non-use of music, and throughout the analysis check for gender differences.

\section{METHOD}

\section{Design}

A survey design was used to investigate relationships between variables and examine differences between groups. Exercisers, including music users and non-users, were invited by direct approach with flyers, through social media and via consequential snowballing to complete an online questionnaire. Data collected included variables related to demographics, formal music training, preferred exercise music, personality, 5k performance and propensity to synchronise to the beat of music while exercising. Both quantitative and qualitative data were collected, with qualitative data such as music choice coded prior to analysis. Trends and frequencies were identified in the data, and inferential tests used to examine differences between groups and relationships between variables. 


\section{Participants}

Participants $(N=282: 159$ women, 117 men, 6 undisclosed) ranged in age from 18 to 65 ( $M$ $=37.68, S D=10.16)$. The majority $(n=259)$ were from the UK, with eight from the rest of Europe, one from Australia, and 14 from the US. Educational level was high, with 230 participants (81.6\%) educated to graduate level or beyond: $27.0 \%$ of the general UK population are educated to this level. Of the remainder, $14(5.0 \%)$ had secondary education (up to age 16), 37 (13.2\%) had tertiary education (age 17-18) and one participant (0.4\%) did not disclose educational level.

\section{Materials}

The survey was administered using SmartSurvey software, using Skip Logic to avoid irrelevant questions: the non-users were not, therefore, asked about their preferred exercise music. Demographic information was collected for age, geographical location and gender; the other variables, measures and questions are outlined below.

\section{ACTIVITIES}

For an overview of what exercise activities participants undertook, a question was included where multiple activities could be checked. A list of common activities was provided for convenience, with a free-text 'other' field to ensure any activity could be included. Participants describing music use during a specific activity identified the activity in a free text field.

\section{PREFERRED EXERCISE MUSIC}

Participants were asked to describe their music use for activities where the music was selfselected. They were able to do so for up to three activities, each of which was self-described: 172 described music choice for a first activity, with only 20 for a second and 5 for a third. Music preferences were therefore analysed for the first choice activity. Choices were coded using the most frequently mentioned style if several tracks were referenced, or the firstmentioned style if several styles were referenced. Choices were categorised initially into 14 
categories then four types, with classifications taken from Rentfrow and Gosling (2003). It was not possible to use the later MUSIC framework (Rentfrow et al., 2012) as there was insufficient information to distinguish between Mellow, Unsophisticated and Contemporary categories (notwithstanding the current limited support for the Mellow category). Categories were augmented to include podcasts and specifically-designed synchronous running music (where the beat corresponds to running cadence e.g. Podrunner, www.djsteveboy.com/podrunner.html): bespoke synchronous running music uses electronic dance styles so was categorised as Energetic and Rhythmic, while podcasts and audiobooks were categorised separately as 'Spoken Word'. In most cases, categorisation was straightforward, with many participants describing a style and giving examples; however, some artists spanned categories and in these cases, the first style listed on their Wikipedia entry was used. Since categorisation is subjective and no academic sources were available, Wikipedia's community authorship and wide artist coverage ensured that descriptions were grounded in consensus and that a replicable, consistent categorisation process was used. The categories and types of music are summarised in Table 1.

TABLE 1. Categorisation of styles

\begin{tabular}{ll}
\hline Type & Styles included \\
\hline Reflective and Complex & Classical, jazz, blues, folk \\
Intense and Rebellious & Alternative, rock, heavy metal \\
Upbeat and Conventional & Country, pop, religious, soundtracks \\
Energetic and Rhythmic & Rap/hiphop, soul/funk, electronica/dance, synchronous \\
& running music \\
Spoken Word & Podcasts and audiobooks \\
\hline
\end{tabular}

Participants were asked for the criteria underpinning their music choices. Options provided were based on the music factors and personal factors in Karageorghis et al.'s conceptual framework (1999) and included intrinsic qualities of the music (speed, style, rhythm, melody and harmony) and extrinsic qualities (memories /associations, 'It's the right kind of music for someone with my social/cultural background). A free-text field was provided for those choosing the 'Other' category, leading to an additional criterion, mood. 


\section{MUSIC USE AND NON-USE}

Participants were asked whether any of their sport or exercise activities included the use of music during the activity itself. Those who used music during at least one activity were classified as users, and those who stated that they did not use music during any sport or exercise activities were classified as non-users. Data was collected on reasons for not listening to music during exercise using free text, some participants providing multiple reasons. The responses were then coded to produce a parsimonious list.

\section{SYNCHRONISATION}

While researchers have assessed synchronisation of movement to a beat through observation, there are no precedents for measuring participants' own perceptions of whether they are synchronising. Categories firstly needed to include synchronising and not synchronising. For synchronising, a further distinction was made between purposeful and accidental synchronisation (the latter found by Hallett and Lamont, 2015). Participants were asked if they chose tracks where they could synchronise their movements to the beat, with response options of frequently/always, sometimes, not at all, or did not intentionally choose such tracks but were sometimes aware that they were synchronising (i.e. accidentally). The 'frequently/always' and 'sometimes' categories were combined for analysis because of there being only 16 frequent synchronisers.

\section{PERSONALITY}

Personality was measured using the Ten Item Personality Inventory (Gosling, Rentfrow \& Swann, 2003) where participants rate how much each of ten pairs of words, relating to the Big Five (Costa \& McCrae, 1988), are 'like them,' using a Likert scale. Each trait has a negative and a positive word-pair. Negative responses are reverse-scored, and the average for the two pairs calculated to score each trait. The TIPI has good test-retest reliability, with correlations at 6 weeks of .72 (Gosling et al., 2003) and has a "reasonable validity" (Jonason, Teicher \& Schmitt, 2011, p.56), with interfactor correlations with the International Personality Item Pool of 1.00 for Extraversion, .99 for Conscientiousness and Emotional Stability, .96 for Agreeableness and.78 for Openness (Ehrhart et al., 2009). 


\section{FORMAL MUSIC TRAINING}

Participants were asked if they had had individual tuition on a musical instrument, differentiating the training from class music lessons where large groups of children may be instructed but not monitored individually. Duration of music training was initially assessed through five categories reflecting Evans, McPherson and Davidson's findings (2013) regarding typical time to withdrawal from instrumental lessons among schoolchildren. For analysis, due to small numbers of respondents in some categories, three levels were used: no training ( $n=$ 106), moderate training (up to 5 years; $n=113$ ) and a high level of training (more than 5 years: $n=63)$.

\section{K RUN/WALK PERFORMANCE}

Time to complete a $5 \mathrm{k}$ run/walk provided performance data that could be utilised widely by participants and provide meaningful comparisons. Participants were asked for the time in minutes they took to cover $5 \mathrm{~km}$ (3.1 miles) by running, walking or a mixture of the two. This protocol was used since 5k is a common event distance: parkruns (www.parkrun.org) held in the UK and internationally have 100,000 participants weekly, and the Cancer Research Race for Life is a first 5k event for many people. The NHS's C25k (Couch to 5k) podcasts are popular with beginner runners. Previous research has also used 5k paces (Meardon, Hamill \& Derrick, 2011, Warren et al., 2011) as a performance measure. A 5k Performance variable was calculated from the times provided using formulae in Glover and Glover (1999) to reflect each participant's performance as a percentage of the speed of a world-class performance by runners of the same age and gender.

\section{Procedure}

Participants were recruited through social media, where the information was shared and retweeted, through a personal website and through flyers and posters at events (e.g. parkrun) and gyms. The publicity materials provided a link to the online survey. Participants were able to read an explanation of the research and gave informed consent through electronic tick boxes; without completing these, they could not progress to the survey. 
Pathways through the survey were set to minimise the number of irrelevant questions. Participants were able to leave fields blank if they did not wish to disclose information. On completion of the survey, a page displayed a thank you message. The data was exported to SPSS for analysis.

\section{Analysis}

Since much of the data was categorical, chi-square tests were used to investigate differences between categories. Effect sizes follow Cohen's criteria (1988) for phi for $2 \times 2$ chi-square tests and Cramer's $V$ for larger tables. Cell-count violations (cell-counts should be 5 or more in $80 \%$ of cells: Pallant, 2010) are indicated in the results. ANOVAs and t-tests were used to compare groups with scale data, with the exception of analysis relating to $5 \mathrm{k}$ Performance. Since this was proportional data calculated as percentages using different denominators, means were affected by weighting therefore non-parametric tests were used. Effect size for scale data was measured using $\eta^{2}$ (as advocated by Levine \& Hullett, 2002). Since six participants did not disclose their gender, their data was not used in gender comparisons, nor could performance ratings be calculated.

\section{Ethics}

Ethical approval was granted by Keele University Ethical Review Panel prior to the research being carried out. Ethical standards met British Psychological Society requirements.

\section{RESULTS}

In the results below, we begin by looking at overall music use, preference and a comparison of use and non-use. We then consider synchronisation, individual differences in terms of personality and formal music training, and finally examine whether music use is related to run/walk speeds. The research questions have been cross-referenced from the relevant sections: Research Question 7, regarding whether gender affects music use in exercise, is covered throughout the different sections of the results.

Over three quarters of participants listened to music to some extent during their exercise sessions. Most participants described music use for just one activity, with only twenty describing more than one: the first-named activities are presented in the Table 2. 
TABLE 2. First-named activity where music was used

\begin{tabular}{|c|c|c|c|c|c|c|}
\hline \multirow[b]{2}{*}{ Activity } & \multicolumn{2}{|c|}{ All participants } & \multicolumn{2}{|c|}{ Women } & \multicolumn{2}{|c|}{ Men } \\
\hline & $n=219$ & $\%$ & $n=132$ & $\%$ & $n=82$ & $\%$ \\
\hline Running/jogging & 129 & 58.9 & 68 & 51.5 & 57 & 69.5 \\
\hline $\begin{array}{l}\text { Exercise to music } \\
\text { classes }\end{array}$ & 29 & 13.2 & 27 & 20.5 & 2 & 2.4 \\
\hline $\begin{array}{l}\text { Gym (unspecified or } \\
\text { cardio) }\end{array}$ & 28 & 12.8 & 23 & 17.4 & 5 & 6.1 \\
\hline Weights & 14 & 6.4 & 4 & 3.0 & 10 & 12.2 \\
\hline Walking & 8 & 3.7 & 5 & 3.8 & 3 & 3.7 \\
\hline Cycling & 7 & 3.2 & 2 & 1.5 & 4 & 4.9 \\
\hline $\begin{array}{l}\text { Unspecified } \\
\text { routine/exercise }\end{array}$ & 2 & 0.9 & 1 & 0.8 & 1 & 1.2 \\
\hline Exercise DVD & 1 & 0.5 & 1 & 0.8 & - & - \\
\hline Skiing & 1 & 0.5 & 1 & 0.8 & - & - \\
\hline
\end{tabular}

The most common activities including those of non-users were running $(n=216)$, followed by cycling $(n=121)$, walking $(n=106)$, gym workouts $(n=100)$, resistance work $(n=93)$ and swimming $(n=87)$.

\section{Music Preference (Research Questions 1 and 2)}

Research Question 1 concerned music preferences. Across all participants, Intense and Rebellious music (including rock, indie and heavy metal styles) was the most popular to listen to during exercise. For the men, it was preferred by more than twice as many participants as the second choice, Energetic and Rhythmic music, whereas for women, preferences were more equally spread across Intense and Rebellious, Upbeat and Conventional, and Energetic and 
Rhythmic music. Table 3 shows the proportions of participants preferring the different types of music and the four participants preferring Spoken Word.

TABLE 3. Preferred type of exercise music

\begin{tabular}{lcccccc}
\hline & \multicolumn{2}{c}{ All participants } & \multicolumn{2}{c}{ Women } & \multicolumn{2}{c}{ Men } \\
\cline { 2 - 7 } Music type & $N$ & $\%$ & $n$ & $\%$ & $n$ & $\%$ \\
\hline Reflective and Complex & 8 & 4.7 & 1 & 1.1 & 6 & 8.2 \\
Intense and Rebellious & 70 & 40.7 & 31 & 32.6 & 38 & 52.1 \\
Upbeat and Conventional & 39 & 22.7 & 32 & 33.7 & 7 & 9.6 \\
Energetic and Rhythmic & 51 & 29.7 & 31 & 32.6 & 18 & 24.7 \\
Spoken Word & 4 & 2.3 & - & - & 4 & 5.5 \\
\hline Total & 172 & 100 & 95 & 100 & 73 & 100 \\
\hline
\end{tabular}

Music preference is represented by the pie charts in Figure 1, which show a clear contrast in preference patterns between men and women (Spoken Word is excluded).
All $(n=282)$
Women $(n=159)$
$\operatorname{Men}(n=117)$
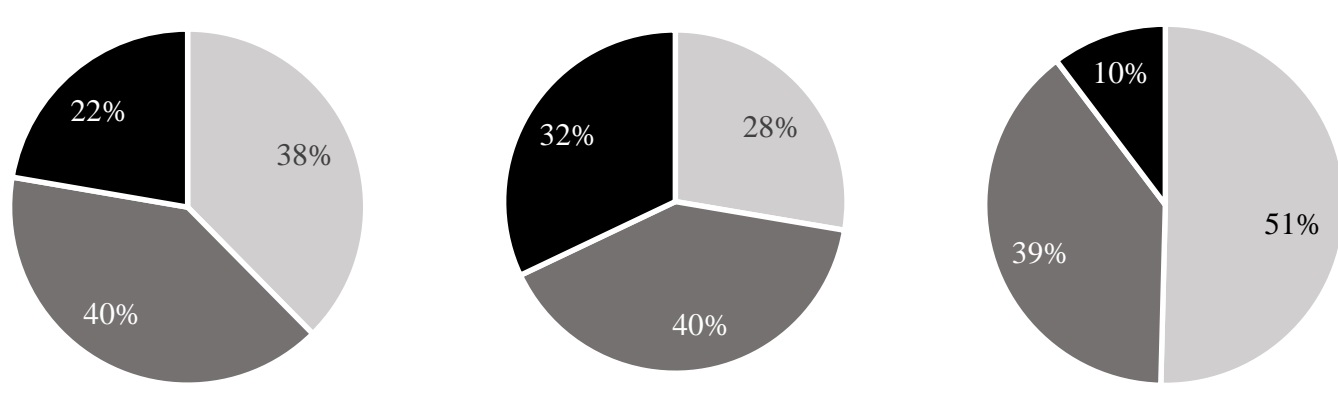

No formal training

$\checkmark=5$ years training

> 5 years training

FIGURE 1. Formal music training: comparison of men and women

(Note: six participants not disclosing their gender are included only in the 'All' chart) 
To address Research Question 2, participants were asked about their criteria for selecting music to exercise to, and their responses are summarised in Table 4. Tempo and style, which are intrinsic musical qualities, were considered most important, with women prioritising tempo and men prioritising style. Extrinsic factors such as memories and associations triggered by the music were considered the third most important factor. Responses in a free-text field for other factors were varied, and included 'Favourite tracks that make me smile,' 'Music I can worship God to,' 'I hit shuffle on the iPod' and 'I honestly don't know.' Chi-square tests did not indicate any relationship between formal music training and music preference.

TABLE 4. Most important factor when choosing exercise music

\begin{tabular}{lcccccc}
\hline & \multicolumn{2}{c}{ All participants } & \multicolumn{2}{c}{ Women } & \multicolumn{2}{c}{ Men } \\
\cline { 2 - 7 } Factor & $N$ & $\%$ & $n$ & $\%$ & $n$ & $\%$ \\
\hline Speed/tempo/bpm & 58 & 32.6 & 41 & 42.3 & 16 & 21.1 \\
Style/genre & 51 & 28.7 & 23 & 23.7 & 27 & 35.5 \\
Memories/ associations & 24 & 13.5 & 12 & 12.4 & 12 & 15.8 \\
Rhythm & 16 & 9.0 & 10 & 10.3 & 6 & 7.9 \\
Melody & 6 & 3.4 & 3 & 3.1 & 3 & 3.9 \\
Mood & 5 & 2.8 & 3 & 3.1 & 2 & 2.6 \\
Cultural fit & 1 & 0.6 & 1 & 1.0 & - & - \\
Other & 17 & 9.6 & 4 & 4.1 & 10 & 13.2 \\
\hline Total & 178 & 100 & 97 & 100 & 76 & 100 \\
\hline
\end{tabular}

The data provided some insight into other-selected music in gyms and classes. Categorisable music descriptions were provided by 37 participants whose first-named activity used other-chosen music: there were 7 gym users, 1 home DVD user and 29 class attendees. Complex and Reflective music was used in 3 cases (8.1\%), for lower intensity classes such as yoga, while classes with higher intensity activity tended to use Upbeat and Conventional (15 cases: $40.5 \%$ ) or Energetic and Rhythmic music (15 cases: $40.5 \%$ ), with less use of Intense and Rebellious music (4 cases: 10.8\%). Twenty-three participants indicated they exercised at the gym (those who did not indicate whether machines or weights were used at home or in a gym were excluded). Sixteen used their own music (69.6\%) while seven listened to the music played by the gym (30.4\%), showing a preference for self-selected music. 
Of the 20 people providing information on more than one activity, 15 described two activities where they chose music to exercise to. In most of these fifteen cases, choice did not vary between activity. In two of the fifteen cases, there was a notable difference: one participant used spoken podcasts for walking and Podrunner podcasts for running (these are dance-music style podcasts with a short spoken introduction preceding around an hour of music), while a second participant described their choice as "rock/dance" for training with weights, and "pop/dance" for boxing.

\section{Non-use of listening material (Research Question 3)}

Those who did not listen to music, audiobooks or podcasts during exercise $(n=63)$ were asked for reasons (multiple responses were possible). The most common response was safety (58.7\%), followed by a wish to focus on the activity (50.8\%). $28.6 \%$ preferred quiet, $22.2 \%$ wished to chat, and $11.1 \%$ wanted to connect with the environment. No participants reported disliking music. Men were more likely than women not to listen to music or spoken word material, and this difference was significant: $\chi^{2}(1, n=276)=6.47, p=.011$, Phi $=-.15$ (small effect). The music use frequencies are shown in Table 5.

TABLE 5. Use of music during exercise sessions

\begin{tabular}{lcccccc}
\hline & \multicolumn{2}{c}{ All participants } & \multicolumn{2}{c}{ Women } & \multicolumn{2}{c}{ Men } \\
\cline { 2 - 7 } Uses music & $N$ & $\%$ & $n$ & $\%$ & $n$ & $\%$ \\
\hline Yes & 219 & 77.7 & 132 & 83.0 & 82 & 70.1 \\
No & 63 & 22.3 & 27 & 17.0 & 35 & 29.9 \\
\hline Total & 282 & 100 & 159 & 100 & 116 & 100 \\
\hline
\end{tabular}

Music use and non-use were also analysed in relation to music training, personality and 5k run/walk performance, and are covered in those sections below.

\section{Synchronisation (Research Question 4)}

Participants were asked whether they synchronised to the beat of self-selected music, either purposefully or by accident. Just over one third reported purposeful synchronisation, while the 
remainder either synchronised accidentally, finding themselves moving to the beat despite having not chosen music to do so, or did not synchronise (or were not aware of doing so). These results are shown in Table 6.

TABLE 6. Propensity to synchronise

\begin{tabular}{lcccccc}
\hline & \multicolumn{2}{c}{ All participants } & \multicolumn{2}{c}{ Women } & \multicolumn{2}{c}{ Men } \\
\cline { 2 - 7 } Synchronisation & $N$ & $\%$ & $n$ & $\%$ & $n$ & $\%$ \\
\hline Purposeful & 60 & 33.7 & 37 & 38.2 & 20 & 26.3 \\
Accidental & 70 & 39.3 & 44 & 45.4 & 25 & 32.9 \\
Non-synchronisers & 48 & 27.0 & 16 & 16.5 & 31 & 40.8 \\
\hline Total & 178 & 100 & 97 & 100 & 76 & 100 \\
\hline
\end{tabular}

Women were more likely to synchronise to the beat than men, and these differences were analysed using a chi-square test. Results were significant: $\chi^{2}(2, n=173)=14.42, p=.002, \mathrm{~V}$ $=.27$ (small effect), with women more likely to synchronise, either purposefully or accidentally, than men. The charts in Figure 2 illustrate the differences between men and women. No effect was found for a relationship between level of formal music training and propensity to synchronise, indicating that the gender differences regarding synchronisation was not attributable to women having higher levels of formal music training.

All

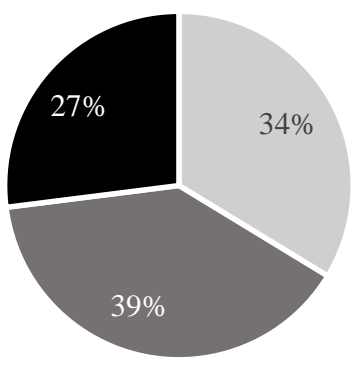

Women

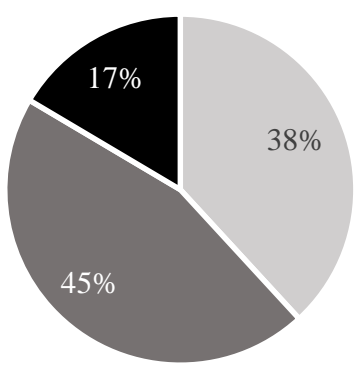

Men

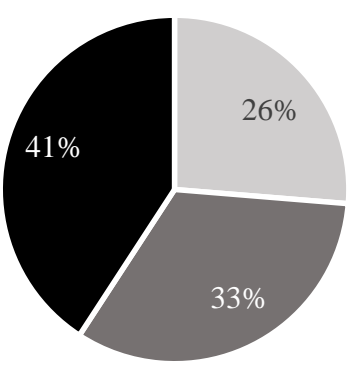
Purposeful
Accidental
Non-synchronisers

FIGURE 2. Propensity to synchronise movement to self-chosen exercise music 
The criteria for music selection varied with propensity to synchronise, as shown in Table 7. Purposeful synchronisers unsurprisingly prioritised tempo, although almost a quarter of accidental synchronisers also considered tempo the most important factor, and it was the second most important factor for both accidental and non-synchronisers after style/genre.

TABLE 7. Propensity to synchronise and most important factor when selecting music.

\begin{tabular}{lcccccc}
\hline & \multicolumn{2}{c}{$\begin{array}{c}\text { Purposeful } \\
\text { synchronisers }\end{array}$} & \multicolumn{2}{c}{$\begin{array}{c}\text { Accidental } \\
\text { synchronisers }\end{array}$} & \multicolumn{2}{c}{ Non-synchronisers } \\
\cline { 2 - 7 } Most important factor & $n$ & $\%$ & $n$ & $\%$ & $n$ & $\%$ \\
\hline Tempo & 34 & 56.7 & 16 & 22.9 & 8 & 16.7 \\
Style/Genre & 9 & 15.0 & 23 & 32.9 & 19 & 39.6 \\
Memories/Associations & 7 & 11.7 & 13 & 18.6 & 4 & 8.3 \\
Rhythm & 4 & 6.7 & 8 & 11.4 & 4 & 8.3 \\
Other & 6 & 9.9 & 10 & 14.2 & 13 & 27.1 \\
\hline Total & 60 & 100 & 70 & 100 & 48 & 100 \\
\hline
\end{tabular}

\section{Personality (Research Question 5)}

The sample's mean personality scores were below the TIPI norms on all five traits, across the sample and within gender groupings. The scores are shown in Table 8 for participants who completed all 10 of the TIPI items. The 'TIPI norms' from Gosling et al. (2003) are also included, in italic type, for comparison.

Personality was a factor in propensity to synchronise. Openness was significant across the sample with a medium-sized effect: $F_{(2,172)}=5.542, p=.005, \eta^{2}=.061$. Post hoc comparisons showed a purposeful synchronisers $(M=5.66, S D=.94)$ had significantly higher levels of Openness than non-synchronisers $(M=5.03, S D=.96)$, Tukey: $p=.003$. For men, there was a medium effect of Extraversion on synchronisation: $F_{(2,71)}=5.56, p=.006, \eta^{2}=$ .13 , between the more Extraverted purposeful synchronisers $(M=5.08, S D=1.57)$ and less Extraverted accidental synchronisers $(M=3.44, S D=1.66), p=.004$ (Tukey). For women, Openness, showed a significant, medium-sized effect: $\left(F_{(2,94)}=3.515, p=.034, \eta^{2}=.070\right)$, with purposeful synchronisers $(M=5.64, S D=1.06)$ more Open than non-synchronisers $(M=$ 4.84, $S D=.89)$, Tukey: $p=.025$. 
TABLE 8. Personality scores

\begin{tabular}{|c|c|c|c|c|c|c|}
\hline & \multicolumn{2}{|c|}{$\begin{array}{c}\text { All } \\
N=267\end{array}$} & \multicolumn{2}{|c|}{$\begin{array}{l}\text { Women } \\
n=154\end{array}$} & \multicolumn{2}{|c|}{$\begin{array}{c}\text { Men } \\
n=108\end{array}$} \\
\hline & $M$ & $S D$ & $M$ & $S D$ & $M$ & $S D$ \\
\hline Agreeableness & 4.89 & 1.19 & 5.11 & 1.21 & 4.61 & 1.09 \\
\hline Norm Agreeableness & 5.23 & 1.11 & 5.32 & 1.11 & 5.06 & 1.10 \\
\hline Conscientiousness & 5.27 & 1.19 & 5.35 & 1.19 & 5.14 & 1.17 \\
\hline Norm Conscientiousness & 5.40 & 1.32 & 5.51 & 1.11 & 5.19 & 1.15 \\
\hline Extraversion & 4.14 & 1.65 & 4.20 & 1.62 & 4.06 & 1.66 \\
\hline Norm Extraversion & 4.44 & 1.45 & 4.54 & 1.47 & 4.25 & 1.41 \\
\hline Openness & 5.23 & 1.11 & 5.26 & 1.12 & 5.20 & 1.04 \\
\hline Norm Openness & 5.38 & 1.07 & 5.40 & 1.06 & 5.34 & 1.09 \\
\hline Stability & 4.64 & 1.40 & 4.49 & 1.41 & 4.83 & 1.39 \\
\hline Norm Stability & 4.83 & 1.07 & 4.66 & 1.45 & 5.13 & 1.31 \\
\hline
\end{tabular}

Norms for $N=1814$ from Gosling et al., 2003, p.526.

There were no significant differences between the personality traits of music users and non-users. For music preference, a small effect was found across the sample for Openness $\left(F_{(3}\right.$, $\left.165)=2.80, p=.042, \eta^{2}=.048\right)$. None of the post-hoc comparisons were significant: the most notable difference ( $p=.101$ ) was between the group preferring Upbeat and Conventional music $(M=5.10, S D=.96)$ and the group preferring Intense and Rebellious music $(M=5.55, S D=$ 1.04), with those preferring Intense and Rebellious music showing higher levels of Openness than those preferring Upbeat and Conventional music. No effects were found when analysis of personality and music preference was carried out by gender.

\section{Music Training (Research Question 6)}

The majority of participants (62\%) had had formal music training. Direct comparison figures are not available, although Hughes (2010) found that $27.2 \%$ of UK adults profess to play a musical instrument. As can be seen in Figure 3, a higher proportion of the women than the men had had formal music training, and for longer than the men. A chi-square test of independence found that these gender differences were significant: $\chi^{2}(2, n=103)=23.42, p<.001, V=.29$ (small effect). Because of the potential of this to be a confounding factor in other analyses, analysis by gender was carried out where possible. 


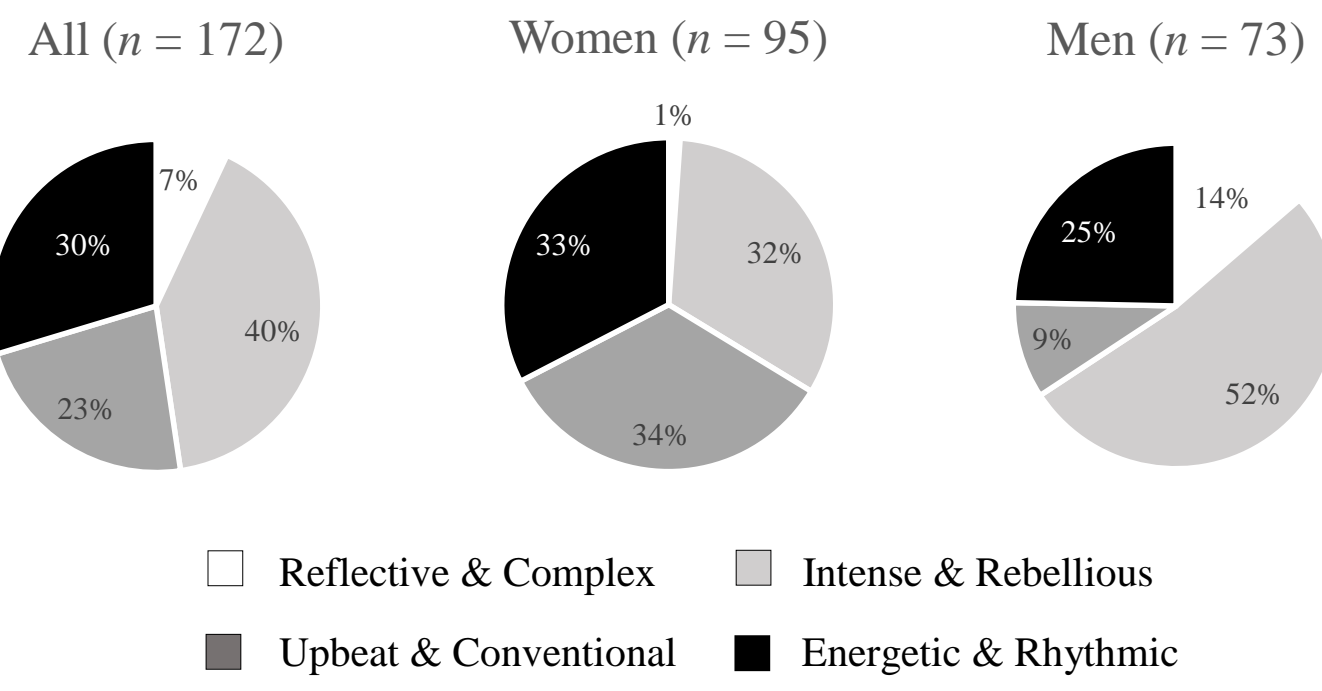

FIGURE 3. Preferred type of exercise music

Chi-square tests were used to explore relationships between formal music training and using music while exercising. There was a small, statistically significant effect: $\chi^{2}(2, n=282)=6.28$, $p=.043, V=.15$, indicating that those with more formal music training were more likely to listen to music while exercising. When analysed by gender, men showed a result with borderline significance: $\chi^{2}(2, n=117)=5.79, p=.055, V=.22$, but there were no significant findings for women: $\chi^{2}(2, n=159)=.762, p=.683, V=.07$ : this suggests a gender influence when all participants were included in the analysis, rather than a confounding effect from women having more formal music training. Comparisons of users and non-users by years of musical training can be seen in Figure 4.

$$
\text { Users }(n=219)
$$

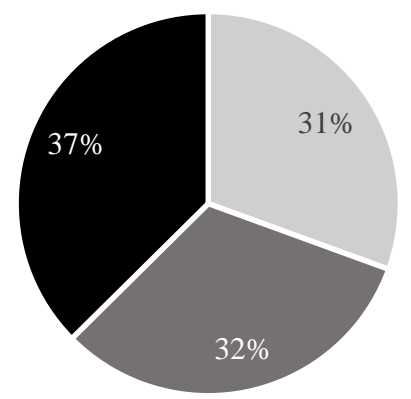

Non-users $(n=63)$

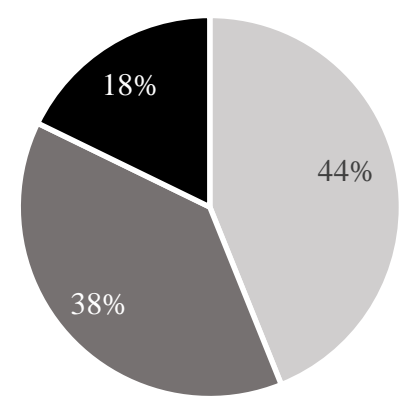

$\square$ No formal training $\square<=5$ years training $\square>5$ years training

FIGURE 4. Formal music training: comparison of music users and non-users 


\section{5k Run/walk Performance (Research Question 8)}

Finally, we consider performance. Participants were asked to report the time in which they were able to cover $5 \mathrm{~km}$. For men the mean time (minutes:seconds) was 22:13 ( $S D=5.82)$ while for women, the mean time was 26:16 $(S D=7.38)$. The times among the sample were faster than those recorded for a large sample of $5 \mathrm{k}$ race times among the UK running community, as can be seen in Table 9. A total of 229 participants provided a 5k time, of which $210(91.7 \%)$ were regular runners.

TABLE 9. Sample 5k times compared with UK average.

\begin{tabular}{|c|c|c|c|c|c|c|c|c|}
\hline \multirow{4}{*}{$\begin{array}{l}\% \text { achieving } \\
\text { time across } \\
\text { UK Jan-Jun } \\
2013\end{array}$} & \multicolumn{4}{|c|}{ Women } & \multicolumn{4}{|c|}{ Men } \\
\hline & \multicolumn{2}{|c|}{ UK average* } & \multicolumn{2}{|c|}{ Sample } & \multicolumn{2}{|c|}{ UK average* } & \multicolumn{2}{|c|}{ Sample } \\
\hline & From & To & & & From & To & & \\
\hline & $(\mathrm{mm}: \mathrm{ss})$ & (mm:ss) & $n$ & $\%$ & (mm:ss) & (mm:ss) & $n$ & $\%$ \\
\hline 1 & 00:00 & $20: 11$ & 10 & 7.94 & 00:00 & $17: 19$ & 8 & 8.25 \\
\hline 5 & 20:12 & $22: 34$ & 8 & 6.35 & $17: 20$ & $18: 52$ & 8 & 8.25 \\
\hline 10 & $22: 34$ & $23: 59$ & 6 & 4.76 & $18: 53$ & $19: 50$ & 6 & 6.19 \\
\hline 20 & $24: 00$ & $25: 47$ & 28 & 22.22 & $19: 51$ & $21: 13$ & 28 & 28.87 \\
\hline 30 & $25: 48$ & $27: 10$ & 23 & 18.25 & $21: 14$ & $22: 21$ & 19 & 19.59 \\
\hline 40 & $27: 11$ & $28: 22$ & 7 & 5.56 & $22: 22$ & $23: 24$ & 6 & 6.19 \\
\hline 50 & $28: 23$ & $29: 30$ & 3 & 2.38 & $23: 25$ & $24: 26$ & 4 & 4.12 \\
\hline 60 & $29: 31$ & $30: 45$ & 8 & 6.35 & $24: 27$ & $25: 34$ & 6 & 6.19 \\
\hline 70 & $30: 45$ & $32: 12$ & 13 & 10.32 & $25: 35$ & $26: 54$ & 4 & 4.12 \\
\hline 80 & $32: 13$ & $34: 04$ & 4 & 3.17 & $26: 55$ & $28: 41$ & 3 & 3.09 \\
\hline \multirow[t]{2}{*}{90} & $34: 05$ & $37: 00$ & 3 & 2.38 & $28: 42$ & $31: 40$ & 2 & 2.06 \\
\hline & $37: 00$ & $65: 00$ & 13 & 10.32 & $31: 40$ & $60: 00$ & 3 & 3.09 \\
\hline
\end{tabular}

*UK average, compiled from Run Britain data on all parkruns and UKA licensed $5 \mathrm{k}$ races in the first half of 2013, with 213,660 performances by women, and 376,427 by men. Times provided for up to 37 minutes for women, and 31:40 for men. The 16 slower participants are accommodated in the bottom line.

The $5 \mathrm{k}$ times of participants were converted to $5 \mathrm{k}$ Performance, a figure representing a percentage of world-class speed for the same gender and age. The differences between men 
$(M d=64.78, n=97)$ and women $(M d=57.58, n=126)$ were significant $(U=3665.00, z=-$ $5.121, p<.001, r=.34$, medium effect), increasing the risk of Type 1 errors, therefore analysis was carried out for each gender separately to avoid confounding results.

When 5k Performances of music users and non-users were compared, the results were significant for women, with non-users achieving higher age-gradings $(M d=62.59, n=20)$ than music users $(M d=55.61, n=106): U=496.50, z=-3.76, p<.001, r=.33$ (medium effect). For men, non-users also achieved higher age gradings $(M d=66.01, n=32)$ than music users $(M d=64.02, n=65)$; the difference was marginal $(p=.077)$. There were no significant findings when the relationships between 5k Performance and (a) Preferred Music Type, (b) Propensity to Synchronise, and (c) Formal Music Training were analysed.

\section{DISCUSSION}

This study explores the intersection of music psychology, media psychology and exercise psychology, examining exercise music choices and application with data collected through a self-report esurvey. The approach was exploratory, with data collected for a broad range of variables. The results provide an insight into exercise music preferences, reasons behind music choices and the decision not to use music, self-perceptions of synchronisation and the extent to which it is used, and how individual differences such as gender, personality and formal training may affect music use in exercise.

Research Question 1 concerned what music was being chosen for exercise. There was a preference for Intense and Rebellious music, particularly when the men's preferences were analysed alone. This kind of music was less frequently reported as being played in classes and on gym PA systems. Participants attending classes were mostly female, and women's exercise music preferences generally were more evenly spread across Intense and Rebellious, Upbeat and Conventional, and Rhythmic and Energetic styles. Intense and Rebellious music might be the best choice of music for classes with higher male attendance, particularly since men gave style as their most important criterion when selecting music. Where individuals had the choice of broadcast music or their own selection (for example, in the gym), the majority chose their own music. Krause et al. (2015) observed this increases arousal levels in everyday listening which may also underpin preference for self-selected music in exercise contexts. 
These findings imply greater liking of heavier music among women Colley (2008) found, perhaps influenced by the exercise context, or because of a wider, older sample than Colley's, where participants were undergraduates. The general preference for upbeat musiccorresponds with Karageorghis and Priest's observations (2012a) that arousal control is key in motivational music use in exercise, and also with North and Hargreave's findings (1996) where participants chose upbeat music for aerobics; most activities described in this study were, like aerobics, moderate to high intensity cardiovascular exercise.

Men's prioritisation of style and women's prioritisation of tempo suggest a different emphasis on mechanisms within the brain according to the BRECVEMA model (Juslin et al., 2013), relating to Research Questions 2 (criteria for selecting music) and 7 (the relationship between gender and music use). Tempo pertains to more basic levels - brain stem and entrainment responses - than style, which suggests cultural background, subjective experiences, and possibly vocal contagion. More research is needed to understand how style influenced those making selections based on it, and to test Clark et al.'s hypothesis (2016) that exercise adherence may be related to the emotional content of exercise music.

The consistency of individuals' music choices for different activities was perhaps surprising, given the scope to build different playlists and carry large libraries with portable listening devices. This may be due to the participants who described music choice for multiple activities referring to quite similar exercises, typically running and an additional cardio activity with large repetitive movements (e.g. cycling).

Research Question 3 concerned why exercisers do not always listen to music. The most common reason for not listening to music was safety; it is not clear whether music would have been used in these situations if this was possible without causing danger. The second most common reason was to focus on an activity, suggesting music is perceived as a distractor which is not always welcome. This may relate to the attentional style discussed earlier (Hutchinson \& Karageorghis, 2013; Razon, 2009), suggesting that music seen from the perspective of a dissociative attentional style and individuals want to focus on how they feel physically, their form and their breathing. This may also explain why those with superior $5 \mathrm{k}$ times were less likely to use music (Research Question 8); rather than it indicating that training with music is detrimental to performance, higher performers may perceive it as distractive and avoid it. However, there music may be beneficial if RPE is reduced; performance should feel easier, increasing speed and providing mastery experiences leading to improved self-efficacy. A dissociative attentional style is more likely to benefit from this as it is more likely to decrease 
RPE at high intensities than an associative style (Hutchinson \& Karageorghis, 2013). When music users were compared with those who exercised without music, they were found to have more formal music training, which may indicate greater importance for music in their lives generally, or greater engagement with it.

Research Question 4 involved perceptions regarding synchronisation. A minority of participants reported synchronising on purpose, with the majority either synchronising accidentally or reporting non-synchronisation. This raises the question of why tempo (bpm) was so influential when selecting music for exercise among accidental and non-synchronisers; only style/genre was considered more important. Tempo carries other qualities beyond facilitating synchronisation, and may relate to Waterhouse et al.'s (2010) finding that participants found faster music more enjoyable motivational, despite not being aware of differences in tempi between different stimuli. It was perhaps surprising that mood was not considered more important, given the role of emotion in everyday music listening (Juslin \& Sloboda, 2010; Skånland, 2013); this suggests that the exercise context has a strong influence on selection criteria, to the extent that these differ substantially from practices in other situations.

Although most participants did not purposefully synchronise, the group who did was larger than expected given previous research (Mendonça et al., 2014; Hallett \& Lamont, 2015). This may be due to a bigger sample than Hallett and Lamont had (their study was also qualitative, rather than collecting data from each participant through the same survey), and could also reflect individual perceptions of synchronous activity differing from research observation. This is an area for further research to investigate this finding.

A number of correlations were found relating tothe relationship between personality, music preference and synchronisation (Research Questions 1, 4 and 5), formal music training's relationship with music use (Research Question 6), and gender differences in music use (Research Question 7). Women were more likely than men to listen to music during exercise, and had more formal music training. They were also more likely to synchronise to the beat of the music. Analysis by gender indicated that women's propensity to synchronise was not related to their level of music training; this provides possible support for Karageorghis et al.'s (2010) suggestion that women's synchronisation practices are related to a socio-cultural environment where dancing and exercise-to-music classes are activities carried out more often by women than men. If this is the case, then synchronisation may show mechanisms of rhythmic entrainment (Clark et al., 2016; Juslin et al., 2013) where response to a stimulus is 
moderated by socio-cultural influences: models of cognitive processes alone could be too reductionist to understand synchronising behaviour. No effect was found for level of musical training on synchronisation across the group, thus Chen et al.'s finding of a positive relationship here (2008) was not supported, possibly due to very high levels of formal musical training among the musicians in Chen et al.'s sample (an average of over 17 years' training).

Several noteworthy findings emerged regarding personality traits, particularly for Openness which was associated with increased likelihood of synchronising. Openness is associated with seeking novel experiences, this may seem to contradict the convention of synchronisation in exercise-to-music classes. However, since the bpm of synchronous exercise music needs to be highly specific to the activity and the individual, asynchronous music could be an easier and perhaps less adventurous option for exercise. Openness was also associated with a preference for Intense and Rebellious music rather than Upbeat and Conventional styles, which is consistent with Rentfrow and Gosling's (2003) results. They also found a relationship between Openness and liking for Reflective and Complex music, which was not found here; this is most likely due to Reflective and Complex music being less of a 'fit' for exercising compared with the other three categories, with few participants exercising to it. Rentfrow and Gosling's association between Extraversion and liking for Upbeat and Conventional music was not found either, although Extraversion was found to be associated with synchronising on purpose among men. There is no clear reason for the gender difference.

Cultural variations across geographical regions may have influenced outcomes, but the sample was predominantly from the UK, with insufficient numbers from outside the UK to carry out meaningful comparisons. With a more international sample, findings may have reflected a different balance of style preference. Recent research using microblog data from Twitter (Hauger, Schedl, Košir \& Tkalčič, 2013) indicates significant differences in styles mentioned from country to country;Brazilian tweeters listened frequently to rock whereas French tweeters more commonly referenced rap and hip hop. It might be expected that higher levels of Intense and Rebellious exercise music would be found in Brazil and higher levels of Energetic and Rhythmic exercise music in France.

The study has some limitations. The sample was highly educated, highly musicallytrained, UK-based and reflecting an age range of 30 to 50. The activities available to this community are therefore reflected, and the particular cultural context and historical positioning of the study inevitably influence musical preferences and practices. Data on ethnicity and ability status was not collected, which limits comparison with samples in other studies. Both 
music dissemination and styles are highly dynamic entities, and repeat studies could help identify changes in exercise music trends over time, and in different populations. It may be fruitful to explore how questions regarding music preference are phrased so that richer data can be collected for analysis, since some of the responses to this survey lacked detail. More freetext response options may have helped here, although this could also have reduced responses through onerous survey length. Future research should focus on narrower topics of interest to facilitate depth of findings without participation becoming overly time-consuming.

Future research needs to recognise the changing nature of music, with regular studies into how personal listening devices are used, how music is accessed (e.g. downloads, streaming, shuffling), and particularly how this differs in exercise contexts compared with everyday listening; this study indicates differences between exercise and general music use. It would be useful to collect data to compare the listening activities of participants in exercise and non-exercise contexts, and also to explore why those who choose to use music during exercise do so. Synchronisation is also worthy of further investigation, since practices were self-reported in the present study; there is little previous investigation of whether exercisers synchronise without being aware of doing so, nor whether they are more likely to synchronise if provided with music at the correct bpm rather than having to source it themselves.

\section{CONCLUSION}

This study presents a number of new findings relating to music use in exercise. It suggests synchronisation may be more widespread than previous research findings indicate, and challenges assumptions that formal music training affects music preferences or propensity to synchronise. Additionally, it suggests to fitness facilities that own music is preferred, presenting an argument for keeping broadcast music at a level where it is not intrusive for those using headphones. It also suggests that Intense and Rebellious styles are the most popular among exercisers. The study has contributed to understanding factors involved with autonomous music use among exercisers, about which little was previously known, and provides impetus for further research exploring these in more depth. 


\section{REFERENCES}

Bharani, A., Sahu, A. \& Mathew, M. (2004). Effect of passive distraction on treadmill exercise test performance in healthy males using music. International Journal of Cardiology, 97, 305-306.

Biagini, M.S., Brown, L.E., Coburn, J.W., Judelson, D.A., Statler, T.A., Bottaro, M., ,..Longo, N.A. (2012). Effects of self-selected music on strength, explosiveness, and mood. Journal of Strength and Conditioning Research, 26(7), 1934-1938.

Chamorro-Premuzic, T., \& Furnham, A. (2007) Personality and music: Can traits explain how people use music in everyday life? British Journal of Psychology, 98 (2), 175-185.

Chen, J.L., Penhune, V.B. \& Zatorre, R.J. (2008). Moving on time: Brian network for auditory-motor synchronization is modulated by rhythm complexity and musical training. Journal of Cognitive Neuroscience, 20(2), 226-239.

Clark, I., Baker, F. \& Taylor, N. (2016). The modulating effectsof music listening on health-realted exercise and physical activity in adults: a systematic review and narrative synthesis. Nordic Journal of Music Therapy, 25(1), 76-104. DOI: 10.1080/08098131.2015.1008558.

Colley, A. (2008). Young People's Musical Taste: Relationship with Gender and Gender-Related Traits. Journal of Applied Social Psychology, 38(8), 2039-2055.

Costa, P., \& McCrae, R. (1988). From Catalog to Classification: Murray's Needs and the Five-Factor Model. Journal of Personality and Social Psychology. 55(2), 258-265.

DeNora, T. (2000). Music in everyday life. Cambridge: Cambridge University Press.

Dillman Carpentier, F.R. \& Potter, R.F. (2007). Effects of music on physiological arousal: explorations into tempo and genre. Media Psychology, 10, 339-363.

Dunn, P., de Ruyter, B., \& Bouwhuis, D. (2011). Toward a better understanding of the relation between music preference, listening behaviour, and personality. Psychology of Music, 40(4), 411-428.

Dyrlund, A.K. \& \& Wininger, S.R. (2008). The effects of music preference and exercise intensity on psychological variables. Journal of Music Therapy, 45(2), 114-134.

Edworthy, J., and Waring, H. (2006). The effects of music tempo and loudness level on treadmill exercise. Ergonomics, 49(15), 1597-1610.

Ehrhart, M.G., Holcombe Ehrhart, K., Roesch, S.C., Chung-Herrera, B.G., Nadler, K. \& Bradshaw, K. (2009). Testing the latent factor structure and construct validity of the Ten-Item Personality Inventory. Personality and Individual Differences, 47, 900-905.

Evans, P., McPherson, G., \& Davidson, J. (2013). The role of psychological needs in ceasing music and music learning activities. Psychology of Music, 41(5), 600-619.

Glover B., \& Glover, S. (1999). The Competitive Runner's Handbook. New York: Penguin Putnam.

Gosling, S., Rentfrow, P., \& Swann, W. (2003). A very brief measure of the Big-Five personality domains. Journal of Research in Personality, 37, 504-528.

Hallett, R., \& Lamont, A. (2015). How do gym members engage with music during exercise? Qualitative Research in Sport, Exercise and Health 7(3), 411-427.

Hargreaves, D. (2012). Musical imagination: Perception and production, beauty and creativity. Psychology of Music, 40(5), 539-557.

Hargreaves, D., MacDonald, R. \& Miell, D. (2005). How do people communicate using music? In D. Miell, R. MacDonald and D. Hargreaves (Eds.), Musical communication (pp. 1-25). Oxford: Oxford University Press.

Hauger, Schedl, Košir \& Tkalčič (2013, November). The Million Musical Tweets Dataset: What can we learn from microblogs. Paper presented at the $14^{\text {th }}$ International Society for Music Information Retrieval Conference, Curitiba, Brazil. Paper retrieved from http://www.cp.jku.at/research/papers/hauger_ismir_2013.pdf.

Hughes, K. (Ed.) (2010). Market Review 2010: Music Industry $2^{\text {nd }}$ Edition. (Middlesex: Keynote). Retrieved from http://ajourneyinmusic.files.wordpress.com/2010/11/music-industry-20101.pdf 
Hutchinson, J. \& Karageorghis, C.I. (2013). Moderating influence of dominant attentional style and exercise intensity on responses to asynchronous music. Journal of Sport and Exercise Psychology, 35, 625-643

Hutchinson, J., Sherman, T., Davis, L., Cawthorn, D., Reeder., N., \& Tenenbaum, G. (2011) The influence of asynchronous motivational music on a supramaximal exercise bout. International Journal of Sport Psychology, 42(2), 135-148.

Hyde, K.L., Lerch, J., Norton, A., Forgeard, M., Winner, E., Evans, A.C. \& Schlaug, G. (2009). Musical training shapes structural brain development. The Journal of Neurosciecne, 29(10), 3019-3025.

Jonason, P.K., Teicher, E.A. \& Schmitt, D.P. (2011). The TIPI's validity confirmed: associations with sociosexuality and self-esteem. Individual Differences Research, 9(1), 52-60.

Juslin, P. (2013). From everyday emotions to aesthetic emotions: Towards a unified theory of musical emotions. Physic of Life Reviews, 10(3). 235-266.

Juslin, P., Harmat, L. \& Eerola, T. (2013). What makes music emotionally significant? Exploring the underlying mechanisms. Psychology of Music, 42(4), 599-623.

Juslin P., \& Sloboda, J. (2010). Introduction: Aims, organization and terminology. In P. Juslin and J. Sloboda (Eds.), Handbook of music and emotion: Theory, research, applications (pp. 3-12). Oxford: Oxford University Press.

Karageorghis, C., \& Priest, D. (2012a). Music in the exercise domain: a review and synthesis (Part I). International Review of Sport and Exercise Psychology, 5(1), 44-66.

Karageorghis, C., \& Priest, D. (2012b). Music in the exercise domain: a review and synthesis (Part II). International Review of Sport and Exercise Psychology, 5(1), 67-84.

Karageorghis, C., Priest, D., Terry, P., Chatzisarantis, N., \& Lane, A. (2006). Redesign an initial validation of an instrument to assess the motivational qualities of music in exercise: The Brunel Music Rating Inventory 2. Journal of Sports Sciences, 24(8), 899-909.

Karageorghis, C., Priest, D., Williams, L., Hirani, R., Lannon, K., \& Bates, B. (2010). Ergogenic and psychological effects of synchronous music during circuit-type exercise. Psychology of Sport and Exercise, 11, 551-559.

Karageorghis, C., Terry, P., \& Lane, A. (1999). Development and initial validation of an instrument to assess the motivational qualities of music in exercise and sport: The Brunel Music Rating Inventory. Journal of Sports Sciences, 17, 713-724.

Knobloch, S. and Zillmann, D. (2002), Mood Management via the Digital Jukebox. Journal of Communication, 52, 351-366.

Krause, A.E., North, A.C. \& Hewitt, L.Y. (2015). Music-listening in everyday life: Devices and choice. Psychology of Music, 43(2), 155-170.

Laukka, P., \& Quick, L. (2013). Emotional and motivational uses of music in sports and exercise: A questionnaire study among athletes. Psychology of Music, 41(2), 198-215.

Levine, T., \& Hullett, C. (2002). Eta Squared, Partial Eta Squared, and Misreporting of Effect Size in Communication Research. Human Communication Research, 28(4), 612-625.

Meardon, S., Hamill, J., \& Derrick, T. (2011). Running injury and stride time variability over a prolonged run. Gait \& Posture, 33(1), 36-40.

Mendonça, C., Oliveira, M., Fontes, L. \& Santos, J. (2014). The effect of instruction to synchronize over step frequency while walking with auditory cues on a treadmill. Human Movement Science, 33, 33-42.

Mitchell, L.A. \& MacDonald, R.A.R. (2006). An experimental investigation of the effects of preferred and relaxing music listening on pain perception. Journal of Music Therapy, XLIII(4), 295-316.

Mitchell, L.A., MacDonald, R.A.R. \& Knussen, C. (2008). An investigation of the effects of music and art on pain perception. Psychology of Aesthetics, Creativity, and the Arts, 2(3), 162-170.

Moens, B., Muller C., van Noorden, L.., Franěk, M., Celie, B., Boone, J., ...Leman, M. (2014). Encouraging spontaneous synchronisation with D-Jogger, an adaptive music player that aligns movement and music. PLoS ONE, 9(12): e114234. DOI: 10.1371/journal.pone/0114234.

Myers, J. (2008). The health benefits and economics of physical activity. Current Sports Medicine Reports, 7(6), 314-316. 
North, A. \& Hargreaves, D. (1996). Responses to music in aerobic exercise and yogic relaxation classes. British Journal of Psychology, 87, 535-547.

North, A., Hargreaves, D., \& Hargreaves, J. (2004). Uses of Music in Everyday Life Music Perception, 22(1), 41-77.

Palmer, S.E. \& Griscom, W.S. (2013). Accounting for taste: Individual differences in preference for harmony. Psychonomic Bulletin and Review, 20, 453-461.

Phillips-Silver, J., Toiviainen, P., Gosselin, N., Piché, O., Nozaradan, S., Palmer, C. \& Peretz, I. (2011). Born to dance but beat deaf: a new form of congenital amusia. Neuropsychologia, 49, 961-969.

Potteiger, J.A., Schroeder, J.M. \& Goff, K.L. (2000). Influence of music on ratings of perceived exertion during 20 minutes of moderate intensity exercise. Perceptual and Motor Skills, 91(3 Pt.1), 848-54.

Priest, D.-L. \& Karageorghis, C.I. (2008). A qualitative investigation into the characteristics and effects of music accompanying exercise. European Physical Education Review, 14(3), 347-366.

Razon, S., Basevitch, I., Land, W., Thompson, B. \& Tenenbaum, G. (2009). Perception of exertion and attention allocation as a function of visual and auditory conditions. Psychology of Sport and Exercise, 10(6), 636643.

Rentfrow, P.J., Goldberg, L.R., Stillwell, D.J., Kosinski, M., Gosling, S.D. \& Levitin, D. (2012). The song remains the same: A replication and extension of the MUSIC model. Music Perception, 30(2), 161-185.

Rentfrow, P., \& Gosling, S. (2003). The Do Re Mi’s of Everyday Life: The Structure and Personality Correlates of Music Preferences. Journal of Personality and Social Psychology, 84(6), 1236-1256.

Skånland, M. (2013). Everyday music listening and affect regulation: The role of MP3 players. International Journal of Qualitative Studies on Health and Wellbeing, 8: 20595 http://dx.doi.org/10.3402/qhw.v8i0.20595 [published online]

Sloboda, J.A., O’Neill, S.A.\& Ivaldi, A. (2001). Functions of music in everyday life: an exploratory study using the Experience Sampling Method. Musicae Scientiae, 5(1), 9-32.

Stanton, R., Happell, B., \& Reaburn, P. (2014). The mental health benefits of regular physical activity, and its role in preventing future depressive illness. Nursing: Research and Reviews, 2014(4), 45-53.

Terry, P. C., Karageorghis, C. I., Mecozzi Saha, A. \& D’Auria, S. (2012). Effects of synchronous music on treadmill running among elite triathletes. Journal of Science and Medicine in Sport, 15, 52-57.

Warburton, D., Charlesworth, S., Ivey, A., Nettlefold, L., \& Bredin, S. (2010). A systematic review of the evidence for Canada's Physical Activity Guidelines for Adults. International Journal of Behavioural Nutrition and Physical Activity, 7(39). DOI: 10.1186/1479-5868-7-39.

Warren, K., Ball, P., Feldman, S., Liu, F., McMahon, R., \& Kelly, D. (2011). Exercise program adherence using a 5-kilometer (5k) event as an achievable goal in people with schizophrenia. Biological Research for Nursing, 13(4), 383-390.

Waterhouse, J., Hudson, P., \& Edwards, B. (2010). Effects of music tempo upon submaximal cycling performance. Scandinavian Journal of Medicine and Science in Sports, 20, 662-669. 